\title{
The Endangered yellow-headed parrot Amazona oratrix along the Pacific coast of Mexico
}

\author{
Tiberio Cesar Monter Rubio-Rico, Katherine Renton, Juan Manuel \\ Ortega-Rodríguez, Alejandro Pérez-Arteaga \\ and RAMÓN CANCINO-MURILLO
}

\begin{abstract}
The yellow-headed parrot Amazona oratrix is categorized as Endangered on the IUCN Red List but little is known about its distribution, particularly along the Pacific coast of Mexico. We used ecological niche models, with presence records from museum collections and historical sightings, overlain on vegetation maps, to predict the historical range of the yellow-headed parrot along the Pacific coast of Mexico. We compared this with the current range of the species, estimated with ecological niche models using presence-absence data from surveys during 2003-2008. We estimate that the range of the yellow-headed parrot along Mexico's Pacific coast has contracted by $79 \%$. The current range may now cover only $18,957 \mathrm{~km}^{2}$, in three main areas. At one of these, a small isolated area on the coast of Jalisco, the species may be vulnerable to extirpation or genetic endogamy. There is a lack of conserved tropical semi-deciduous forest, which provides optimal habitat for reproduction of this parrot, within the current range of the species. Only the south, along the coast of Oaxaca, has extensive areas of this habitat. There are only three, small, protected areas within the species' current range. Conservation strategies need to be implemented to restore connectivity between the three main areas of the current range of the yellow-headed parrot on the Pacific coast of Mexico.
\end{abstract}

Keywords Amazona oratrix, ecological niche modelling, fragmentation, historical distribution, Mexico, tropical dry deciduous forest, yellow-headed parrot

\section{Introduction}

The yellow-headed parrot Amazona oratrix is catego1 rized as Endangered on the IUCN Red List (Collar et al., 2000; IUCN, 2008). The species occurs in Mexico, Belize, Guatemala and Honduras but has its broadest distribution in Mexico, with three races of $A$. oratrix

Tiberio Cesar Monterrubio-Rico, Juan Manuel Ortega-Rodríguez, Alejandro Pérez-Arteaga (Corresponding author) and Ramón CAncino-Murillo Laboratorio de Manejo y Conservación de Fauna Silvestre, Facultad de Biología, Universidad Michoacana de San Nicolás de Hidalgo, Edificio R, Ciudad Universitaria, Morelia, Michoacán 58194, México. E-mail aperezarteaga@mac.com

Katherine Renton Estación de Biología Chamela, Instituto de Biología, Universidad Nacional Autónoma de México, San Patricio, Jalisco, México

Received 20 May 2009. Revision requested 26 August 2009.

Accepted 17 September 2009. oratrix along the Gulf coast, A. oratrix magna along the Pacific coast and A. oratrix tresmariae restricted to the Tres Marias Islands (Howell \& Webb, 1995; Collar et al., 2000).

The species is reported from sea level to $900 \mathrm{~m}$; it inhabits dense deciduous, semi-deciduous and riparian forests, as well as semi-open areas with scattered trees (Ridgely, 1981; Howell \& Webb, 1995; Collar et al., 2000). It has been recorded feeding on the seeds of tree species characteristic of tropical semi-deciduous forest, such as Astronium graveolens, Crataeva tapia and Sideroxylon capiri, as well as on the fruits of Ficus insipida (Renton, 2002), and nests in cavities in large mature trees of A. graveolens, Bursera arborea, Ebenopsis ebano and Sideroxylon palmeri (Enkerlin-Hoeflich, 1995; Renton, 2002). In Mexico the original range of the yellowheaded parrot has contracted, by an estimated $31 \%$, because of habitat loss (Rios-Muñoz, 2002). However, this estimate was based on ecological niche model vegetation analysis using historical presence records from museum collections; this may overestimate extent of occurrence and does not take into account absence records. Ecological model predictions have rarely been verified in the field, and few studies have compared the historical and current ranges of threatened species.

Studies that compared historical reports with estimates of current range based on surveys have noted range contractions because of anthropogenic impacts. For example, the endemic Oncocyclus irises of Lebanon have been extirpated from $50 \%$ of locations known from herbarium collections because of habitat loss and fragmentation (Saad et al., 2009), and hunting was the main cause of the decline in range and population density of the pileated gibbon Hylobates pileatus in Thailand (Phoonjampa \& Brockelman, 2008).

The status and distribution of the yellow-headed parrot along the Pacific coast of Mexico is poorly known (Ridgely, 1981), although the species has been reported as uncommon and local in Colima (Schaldach, 1963) and Oaxaca (Binford, 1989) and has been locally extirpated in some parts of its range as a result of habitat loss and capture for trade (Monterrubio-Rico et al., 2007). There is particular concern for the status of this species along the Pacific coast of Mexico, which has experienced the highest rates of deforestation in the country (Trejo \& Dirzo, 2000). Few studies have compared historical and current ranges of Psittacidae species using historical records and contemporary presence-absence data. One exception is a local-scale study comparing the past and present range of the yellow-headed parrot along the 
coast of Michoacan, Mexico, where recent presence and absence records from field surveys indicate the species occupies only $46 \%$ of its presumed historical range (MonterrubioRico et al., 2007). Otherwise, little is known about the current range of this species along the Pacific coast of Mexico and how this compares to the species' historical range. Such information is required for a full assessment of conservation status and for the development of an appropriate conservation strategy.

Here, we estimate the historical range of the yellowheaded parrot along the Pacific coast of Mexico based on historical records and suitable ecological conditions for the species. We conducted surveys throughout this presumed historical range to evaluate the species' current distribution along this coast, and we assess the conservation status of the yellow-headed parrot in this area based on habitat availability and occurrence of the species in protected areas.

\section{Methods}

\section{Surveys}

During 2003-2008 we conducted field surveys to obtain occurrence data for the yellow-headed parrot throughout its range along the Mexican Pacific coast. We conducted 798 surveys at 437 unique localities in all coastal regions from Jalisco to the Isthmus of Tehuantepec, Oaxaca, including some areas of the Sierra Madre del Sur and the lower Balsas Basin in Michoacan and Guerrero. Most of these surveys were at altitudes of $0-900 \mathrm{~m}$ but some localities up to 2,000 $\mathrm{m}$ were also surveyed.

We surveyed in both breeding (January-May) and nonbreeding (June-December) seasons for $>2$ years in Oaxaca, 3 years in Guerrero and Colima, and $>5$ years in Jalisco and Michoacan. Field survey methods included point counts and observations from vantage points (Marsden, 1999; Bibby et al., 2000). Point counts were made during the first 3 hours after sunrise and vantage point observations were conducted in the 2 hours prior to sunset, when parrots are most active (Salinas-Melgoza \& Renton, 2005). Point counts were along a transect line consisting of 10 point-count locations $300 \mathrm{~m}$ apart, of 10 minutes duration at each point (Marsden, 1999; Bibby et al., 2000). The data recorded included time of day, number of individuals, detection method (observed or vocalizing), activity (perched, flying or feeding), distance from the observer, and observations of group size, direction of flight and feeding.

\section{Ecological niche modelling}

We estimated the historical and current ranges of the yellow-headed parrot using the genetic algorithm for rule set prediction (GARP) methodology (Stockwell \& Peters, 1999; Peterson, 2001) as this algorithm has been tested, generates consistent, accurate models under difficult test conditions, and performs well in comparative studies (Stockwell \& Peterson, 2002; Peterson et al., 2007; Tsoar et al., 2007). In addition, the geographical scale and amount of data available for this study were adequate to maximize the power of GARP (Stockwell \& Peterson, 2002).

The GARP ecological niche model was based on seven environmental layers: elevation, aspect, slope and a compound topographic index, from USGS (2009), and proportional estimates for woody vegetation, herbaceous vegetation and bare ground from the Vegetation Continuous Fields collection (GLCF, 2010), all derived from MODIS imagery. Data layers were re-sampled to $30^{\prime \prime}$ cell size $($ c. $1 \mathrm{~km})$.

We selected presence records to avoid a high concentration of records in a particular locality, especially when records differed by only a few longitudinal or latitudinal seconds (Martínez-Meyer, 2005). We used 82 unique localities to build the models: four for Jalisco, 31 for Michoacan, 11 for Guerrero and 36 for Oaxaca. To optimize model performance we developed 100 replicate models and then considered a best subset based on optimal error distributions for individual replicate models (Anderson et al., 2003). The 20 models with omission error rates $<10 \%$ were retained initially, and then the 10 closest to the predicted median area (commission error index) were selected as the best model subset (Anderson et al., 2003). These were summed to produce a final composite map representing the geographical distribution of suitable environmental conditions for the yellow-headed parrot.

To validate the models we set aside $50 \%$ of the occurrence locations as extrinsic testing data for an external test of model quality (Peterson et al., 2002; Martínez-Meyer, 2005). We used the set of localities for each state independently to model the species' entire range, obtaining models for all combinations of states and withholding all the localities in the test states to measure model accuracy (Peterson et al., 2002). We used a conservative threshold, to avoid overpredicting presence areas, by analysing the coincidence of field records with the number of independent models that predicted presence on a pixel-by-pixel basis. In the most accurate models $97 \%$ of the field records coincided with 8-10 models predicting presence. We therefore considered only those areas with the highest coincidence of 8-10 models predicting presence. The coincidence between independent test data and the geographical predictions was evaluated using a $\chi^{2}$ goodness of fit test to determine whether test points fell into regions of predicted presence more often than expected by chance.

\section{Historical range}

To estimate the historical range of the yellow-headed parrot along the Pacific coast of Mexico we used collection records 
with geographical coordinates from 21 museum specimens (1858-1961) of the yellow-headed parrot (Navarro et al., 2003). We also reviewed published sources to obtain historical sightings of the species for 1950-2000 (Friedmann et al., 1950; Miller et al., 1957; Schaldach, 1963; Rowley, 1984; Villaseñor-Gómez, 1988; Binford, 1989; Navarro, 1992; ChávezCastañeda et al., 1996; Howell, 1999).

The ecological niche model incorporated the vegetation maps for Mexico (Rzedowski, 1994), digital elevation data and a digital map of the biogeographical regions of Mexico. We modelled the distribution of the yellow-headed parrot within the limits of the appropriate elevation $(\leq 900 \mathrm{~m})$, vegetation types and known documented range of the species (Forshaw, 1989; Howell \& Webb, 1995). We assumed that the ecological requirements of the species have not changed in the past 150 years.

\section{Current range}

We used presence and absence records from field surveys and ecological niche modelling to estimate the species' current range. The inaccessibility or level of insecurity in some areas along the Pacific coast made the application of a systematic grid system for determining presence-absence impractical. We also wished to apply a conservative method so as not to overestimate potential extirpation of the species. We therefore analysed the presence and absence records in each of the coastal municipalities of the Pacific region. Municipalities provide a practical unit, and government development programmes, and decisions concerning land use, development and forest loss, are at the municipal level.

Within each municipality we limited estimates of range to areas covered by suitable vegetation for the yellowheaded parrot, and the species was considered present throughout the area where the models predicted suitable ecological conditions. To estimate the area where the species has been extirpated we incorporated absence data from the surveys in areas where the model predicted presence. In municipalities where the species was recorded as present for some localities but absent in others we considered the species as present for that municipality, following the assumption that presence of the species in one locality and absence from a neighbouring locality could be because of sampling error and/or insufficient sampling effort.

\section{Habitat availability and protected areas}

To evaluate habitat availability for the yellow-headed parrot within its current range we used vegetation and land cover statistics from the National Forest Inventory for Mexico (SEMARNAP-UNAM, 2000). We considered six vegetation categories from the Inventory: temperate forest (which includes mixed pine-oak forests and cloud forests), transformed agricultural land (all types of agricultural land, horticultural land or pastures), conserved and modified tropical dry deciduous forest, and conserved and modified tropical semi-deciduous forest.

We used a $\chi^{2}$ goodness of fit test and Bonferroni confidence intervals to determine whether the frequency of presence localities for the yellow-headed parrot in each vegetation type was proportional to habitat availability within the current distribution of the species along the Pacific coast (Nue et al., 1974; Byers et al., 1984). A set of simultaneous $95 \%$ confidence intervals was constructed for the proportion of presence localities by habitat type. The observed frequency of localities in a specific habitat type differs significantly from that expected where the expected proportion of localities based on habitat availability falls outside the 95\% confidence interval (Byers et al., 1984). Finally, we evaluated the protected areas within the current distribution of the yellow-headed parrot on the Pacific coast.

\section{Results}

\section{Historical and current range}

We estimated that the historical range of the yellow-headed parrot along the Pacific coast covered 90,470 $\mathrm{km}^{2}$ (Fig. 1a). We registered the species in $118(27 \%)$ of the 437 localities that we surveyed, and estimated the current range to be $18,957 \mathrm{~km}^{2}$ (Fig. 1b), i.e. a reduction of $79 \%$. All the models were highly significant at $\mathrm{P}<7.2 \times 10^{-10}$, demonstrating a high predictive value for the independent test points.

We visited 11 localities with historical presence records (for 1858-1964) for the yellow-headed parrot and confirmed presence in only four localities (three in Oaxaca and one in Michoacan). The highest percentages of presence records from surveys were in Oaxaca and Michoacan, and the model for the current range also predicted the largest area with suitable ecological conditions for the yellow-headed parrot in these areas (Fig. 1b). The species has probably been extirpated from most of Colima state, and in Jalisco and Guerrero the species occurred in $<10 \%$ of the localities surveyed. Although the yellow-headed parrot persists at the geographical extremes of its range along this coast, from Jalisco in the north to Oaxaca in the south, the area occupied by the species has shrunk in all the states where it occurred historically. The current range of the yellowheaded parrot along the Pacific coast of Mexico is now discontinuous, fragmented into three areas (Fig. 1b).

The smallest, most isolated section of the current distribution is on the coast of Jalisco, where the ecological niche model estimated an area of $1,593 \mathrm{~km}^{2}$ (8\% of the current distribution) with suitable ecological conditions for the species. Of 50 localities surveyed in Jalisco we registered the yellow-headed parrot in only four ( $8 \%)$, reflecting its 

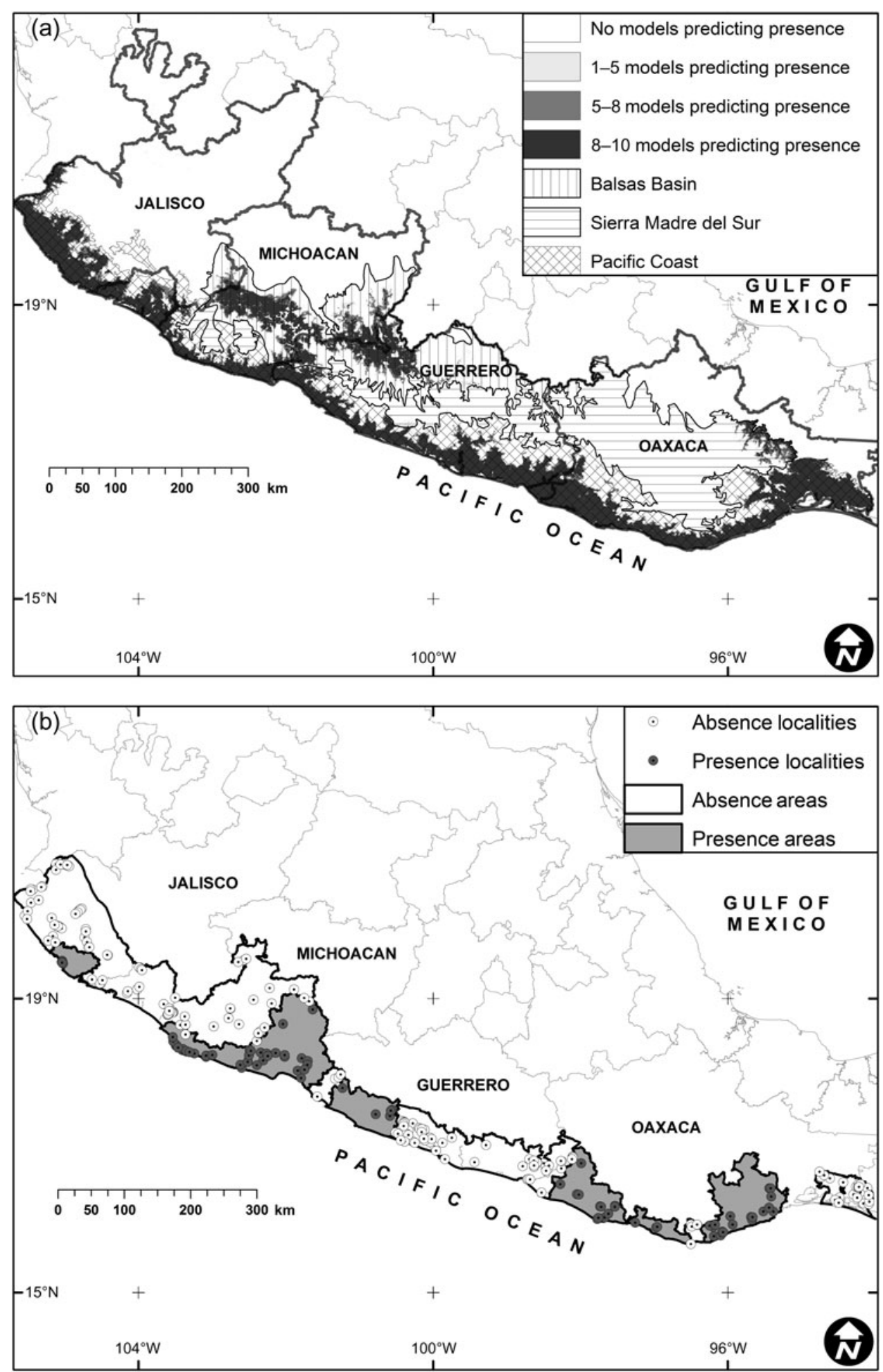

FIG. 1 (a) Historical range of the yellow-headed parrot Amazona oratrix along the Mexican Pacific coast, estimated using ecological niche models (see text for details). (b) Reduced current range, determined from field surveys and habitat availability. The extent encompassed by the thick black line is the estimated historical distribution from (a). Grey shading within this indicates areas with suitable habitat where the yellow-headed parrot still occurs and no shading indicates areas where the species has apparently been extirpated.

highly local distribution. We recorded the yellow-headed parrot as absent in an extensive area from the southern coast of Jalisco, through Colima state, to the municipality of
Coahuayana on the northern coast of Michoacan. It is likely that the yellow-headed parrot has been extirpated from this part of its historical range. 
The largest area within the current range of the yellowheaded parrot is along the coast of Michoacan and the northern coast of Guerrero, where the ecological niche model predicted suitable ecological conditions for the species in $8,905 \mathrm{~km}^{2}$, i.e. $47 \%$ of the entire estimated current range of the yellow-headed parrot on the Pacific coast (Table 1). Of 164 localities surveyed in Michoacan we registered the species in 55 (34\%). Five municipalities contained most of the current range of the yellow-headed parrot in this central region: Aquila, Lázaro Cárdenas and Arteaga in Michoacan, and La Union and Coahuayutla in Guerrero. We recorded a distributional gap along the coast of Guerrero in the municipality of Jose Azueta (Fig. 1b), where the species has probably been extirpated. There was another large gap to the south, where the yellow-headed parrot is absent from 10 coastal municipalities in central and south Guerrero (Fig. 1b).

The third area of the current range is along the coast of Oaxaca (Fig. 1b). The ecological niche model estimated an area of $8,458 \mathrm{~km}^{2}$ with suitable habitat conditions in this region, i.e. $45 \%$ of the species' current range along the Pacific coast. Six municipalities along the coast of Oaxaca comprise the main current range of the yellow-headed parrot: Santiago Jamiltepec, Pinotepa Nacional, Salina Cruz, Santo Domingo Tehuantepec, San Gabriel Mixtepec and Santiago Pinotepa Nacional. We did not record yellow-headed parrots at any localities on the Isthmus of Tehuantepec (Fig. lb).

\section{Habitat availability and protected areas within the current distribution}

We recorded the yellow-headed parrot at altitudes of o-896 m, with $76 \%$ of presence records below $400 \mathrm{~m}$. Most presence records were below $200 \mathrm{~m}$ ( $48 \%$ of records), and only $24 \%$ of presence records at $400-900 \mathrm{~m}$. Other than transformed agricultural land the predominant vegetation type in the current range of the yellow-headed parrot is tropical dry deciduous forest, both conserved and modified (Table 1). Most of the localities where we observed yellowheaded parrots were in tropical dry deciduous forests (53\%; Table 2). Tropical semi-deciduous forest covers $19 \%$ of the species' current distribution (Table 1) but 33\% of localities where the species was recorded were in this vegetation type
(Table 2). Transformed agricultural land covered the largest area within the species' current distribution (Table 1) but contained few of the localities where the species was recorded (Table 2).

The proportion of presence localities in the various vegetation types differed significantly from that expected by habitat availability $\left(\chi_{5}^{2}=46, \mathrm{P}<0.001\right)$. In particular, there were significantly fewer presence localities for the yellowheaded parrot in transformed agricultural land than would be expected by the availability of this land-use type (Table 2).

The coast of Oaxaca has the greatest extent $\left(3,336 \mathrm{~km}^{2}\right)$ of conserved forests and, in particular, is the region with the greatest extent and proportion of conserved tropical semideciduous forest within the current range of the yellowheaded parrot (Table 1). The central portion of the current range of the yellow-headed parrot in Michoacan-Guerrero contained $2,954 \mathrm{~km}^{2}$ of conserved forests but the proportion of conserved tropical semi-deciduous forest is low (Table 1).

We confirmed the presence of the yellow-headed parrot in only three protected areas along the Pacific coast: the Chamela-Cuixmala Biosphere Reserve $\left(131 \mathrm{~km}^{2}\right)$ in Jalisco and the Lagunas de Chacahua $\left(142 \mathrm{~km}^{2}\right)$ and Huatulco (119 $\mathrm{km}^{2}$ ) national parks in Oaxaca. The extent of protected area within the current distribution of the species is only $392 \mathrm{~km}^{2}$.

\section{Discussion}

We estimate that the historical range of the yellow-headed parrot along the Pacific coast of Mexico has contracted by $79 \%$. The estimated current range along this coast may now cover only $18,957 \mathrm{~km}^{2}$ and is fragmented into three main areas. This reduction is greater than the $31 \%$ reduction based on habitat loss estimated by Rios-Muñoz (2002) for both the Pacific and the Gulf coast distributions of the species in Mexico. However, this estimate was based only on presence records from museum collections, without field verification. Our estimate of the historical range is based on presence records combined with vegetation analysis and may potentially overestimate the original range of the species, although we attempted to limit this within the boundaries of suitable altitude and known range. Our incorporation of both presence and absence records for evaluation of the

TABLE 1 Habitat availability $\left(\mathrm{km}^{2}\right)$ for the yellow-headed parrot Amazona oratrix in the three main areas of its current range, and overall (with percentage), along the Pacific coast of Mexico (Fig. 1b).

\begin{tabular}{lccrc}
\hline Land cover & Jalisco & Michoacan-Guerrero & Oaxaca & Entire current range (\%) \\
\hline Transformed agricultural land & 504 & 3,021 & 2,531 & $6,057(32.0)$ \\
Conserved tropical dry deciduous forest & 646 & 2,565 & 2,031 & $5,242(27.7)$ \\
Modified tropical dry deciduous forest & 149 & 2,150 & 837 & $3,137(16.5)$ \\
Modified tropical semi-deciduous forest & 170 & 396 & 1,361 & $1,927(10.2)$ \\
Conserved tropical semi-deciduous forest & 56 & 389 & 1,305 & $1,750(9.2)$ \\
Mixed temperate pine-oak forest & 67 & 386 & 387 & $840(4.4)$ \\
Total & 1,593 & 8,905 & 8,458 & 18,957 \\
\hline
\end{tabular}


TABLE 2 Bonferroni confidence intervals for proportion of yellow-headed parrot presence localities in each habitat type compared to the proportion expected from habitat availability (Table 1) within the species' current distribution along the Pacific coast of Mexico (Fig. 1b).

\begin{tabular}{llll}
\hline Habitat type & $\begin{array}{l}\text { Proportion of } \\
\text { presence localities }\end{array}$ & $\begin{array}{l}\text { Proportion of } \\
\text { localities expected }\end{array}$ & $\begin{array}{l}\text { Bonferroni } \\
\text { confidence intervals }\end{array}$ \\
\hline Transformed agricultural land & 0.07 & 0.32 & $0.01 \leq \mathrm{obs} \leq 0.13^{*}$ \\
Conserved tropical dry deciduous forest & 0.39 & 0.28 & $0.27 \leq \mathrm{obs} \leq 0.51$ \\
Modified tropical dry deciduous forest & 0.14 & 0.17 & $0.05 \leq \mathrm{obs} \leq 0.22$ \\
Modified tropical semi-deciduous forest & 0.20 & 0.10 & $0.10 \leq \mathrm{obs} \leq 0.30$ \\
Conserved tropical semi-deciduous forest & 0.13 & 0.09 & $0.05 \leq \mathrm{obs} \leq 0.21$ \\
Mixed temperate pine-oak forest & 0.08 & 0.04 & $0.01 \leq \mathrm{obs} \leq 0.13$ \\
\hline
\end{tabular}

${ }^{*} \mathrm{P}<0.05$

current distribution demonstrated areas with suitable habitat, where the ecological model predicted presence, but where we did not locate the species. This suggests that the reduction in range is caused by factors other than habitat loss, such as capture for trade, which is not reflected in presence-only habitat-based models (Monterrubio-Rico et al., 2007).

The yellow-headed parrot is the most highly valued Amazon parrot in trade because of its attractive plumage and ability to imitate human speech (Ridgely, 1981; Cantu et al., 2007). In 1979-1980, prior to its listing on CITES, Mexico exported $>2,700$ yellow-headed parrots to the USA (Roet et al., 1981). During the early 1980s the Pacific coast of Mexico was the main capture zone for trade in psittacines, with $86 \%$ of the parrots captured in Mexico in 1982-1983 coming from this region (Iñigo-Elias \& Ramos, 1991). It is estimated that at least 1,000 yellow-headed parrots per year are still illegally captured in Mexico (Cantu et al., 2007), and the yellow-headed parrot is the Mexican psittacine most frequently seized at the US border (Cantu et al., 2007). This intense pressure has decimated wild populations of the species, leaving areas where the species is no longer present even though suitable habitat remains.

While it is difficult to demonstrate and interpret real absence for a species within its range (Martínez-Meyer, 2005), we consider our estimates robust because we adopted a conservative approach and considered the yellow-headed parrot as present in a municipality unless we had sufficient evidence that the species had been extirpated from the area. Nevertheless, the species may still occur in some areas but in such low numbers that greater survey effort is required to detect its presence. The yellowheaded parrot could theoretically repopulate areas of suitable habitat should the pressure of capture for trade be eased or conservation actions implemented.

Another concern for conservation of the yellow-headed parrot along the Pacific coast of Mexico is the potential isolation of populations in three areas. In particular, the population in Jalisco may be vulnerable to extirpation or genetic endogamy. It is vital to maintain populations of the yellow-headed parrot throughout its range and to restore connectivity between the three areas where it still occurs.
Research is required to evaluate potential corridors between these areas. Strategies to restore connectivity for the yellowheaded parrot along the Pacific coast would also benefit other threatened species, such as the endemic lilac-crowned parrot Amazona finschi, which relies on continuous areas of tropical semi-deciduous forest for nesting (Monterrubio-Rico et al., 2009).

The lack of conserved tropical semi-deciduous forest within the current range of the yellow-headed parrot is an additional concern for the maintenance of reproductively healthy populations. The species requires natural cavities in large mature trees for nesting (Enkerlin-Hoeflich, 1995). It can nest in isolated trees in semi-open areas or introduced pastures where suitable forest habitat is located within foraging distance (Enkerlin-Hoeflich, 1995; MonterrubioRico et al., 2007). However, modified or fragmented forests have few suitable cavities for nesting (Enkerlin-Hoeflich, 1995; Marsden \& Pilgrim, 2003), and the yellow-headed parrot only has low nest success in these modified habitats (Enkerlin-Hoeflich, 1995). In our field surveys we located the species less than would be expected, based on area, in transformed agricultural land, indicating that parrots avoid these areas. Hence, conserved tropical semi-deciduous forest is probably the optimal habitat for reproduction of the yellow-headed parrot. The greatest extent of this forest type is along the coast of Oaxaca and this area is therefore a conservation priority. Strategies for restoration of tropical semi-deciduous forest with native tree species that are used for nesting and foraging by yellow-headed parrots would be of value along the coast of Michoacan-Guerrero.

There are few protected areas within the current range of the yellow-headed parrot along the Mexican Pacific coast. The importance of protected areas as refuges for threatened species is highlighted by the Chamela-Cuixmala Biosphere Reserve in Jalisco, which was the only site in this area where we detected the yellow-headed parrot and may be the last refuge for the species in this region (Renton, 2002). Additional protected areas are required in Michoacan and Guerrero. Expansion of the Huatulco and Lagunas de Chacahua national parks is required along the coast of Oaxaca. Ideally, a larger protected area is required in coastal Oaxaca to conserve the considerable extent of tropical 
semi-deciduous forest there. Protected areas can serve as invaluable refuges providing source populations able to reoccupy available habitat outside reserves. However, the three small protected areas within the Pacific range of the yellow-headed parrot protect only $2 \%$ of the species' current range. The long-term survival of the yellow-headed parrot along the Pacific coast cannot be secured with the existing protected areas system. It is essential therefore to develop alternative conservation strategies such as collaborative agreements with local communities to conserve forest habitats outside protected areas.

Any strategy to restore wild populations and restore connectivity within the current range of the yellow-headed parrot will depend on reducing the impact of illegal capture for trade. Recently, the Mexican government approved a ban on the capture and trade of all parrot species in Mexico (DOF, 2008). The NGOs Teyeliz and Defenders of Wildlife also implemented a nationwide campaign to promote awareness of the critical conservation status and threats faced by many Mexican parrot species, with a focus on the yellow-headed parrot. At the local level, outreach programmes are required that involve local people in conservation of the species and promote alternative strategies for sustainable use, such as nature tourism to observe nesting and foraging yellow-headed parrots in the wild. Such programmes are particularly required in the municipalities that contain the greatest extent of the species' range.

Our recommendations have now been incorporated into the Yellow-Headed Parrot Species Recovery Programme being developed by the Secretariat for the Environment and Natural Resources and the National Commission for Protected Areas (CONANP) in collaboration with the Mexican Parrot Subcommittee. The yellow-headed parrot was identified as a priority species for conservation by this Subcommittee (SEMARNAP-INE, 2000). During 2008-2009 we participated in workshops, organized by the Subcommittee and the Priority Species Directorate of CONANP, to develop a recovery programme for the species. This specifies strategies for the protection, management and restoration of wild populations and habitat, and priorities for research, monitoring and outreach activities. The recovery programme identifies government agencies that could participate in the implementation of conservation strategies, and establishes a time line for action. The Priority Species Directorate of CONANP will have responsibility for evaluation and monitoring of the recovery programme. Any failure to implement the recovery programme would probably result in further reduction of the species' range along the Pacific coast and possibly the extirpation of the species along the coast of Jalisco.

\section{Acknowledgements}

We are grateful for the field assistance provided by A. SalinasMelgoza, E. López-Córdova, B. Fabián-Turja, B. Santiago-
Valencia, L. Tellez-García, M. de Labra Hernández, I. Carrillo Acevedo, M. Alvarez-Jara and T. Sanchez-Martinez. We thank A. Navarro-Siguenza for providing historical data collections from the Atlas of Birds of Mexico. Financial support was generously provided by Coordinación de Investigación Científica in Universidad Michoacana de San Nicolás de Hidalgo (project number 8.6), the Comisión Nacional para Ciencias y Tecnología (CONACYT; installation project $135702-\mathrm{V}$ ), and the Fondo Sectorial de Investigación Ambiental of the Secretaria del Medio Ambiente y Recursos Naturales (SEMARNAT) and CONACYT (Project 2002-C01-00021). Research permits were provided by the Dirección General de Vida Silvestre, SEMARNAT. We thank the Facultad de Biología at Universidad Michoacana de San Nicolás de Hidalgo, the Fundación Ecológica de Cuixmala and the Estación de Biología Chamela of the Instituto de Biología, Universidad Nacional Autónoma de México, for their continued support.

\section{References}

Anderson, R.P., Lew, D. \& Peterson, A.T. (2003) Evaluating predictive models of species distributions: criteria for selecting optimal models. Ecological Modelling, 162, 211-232.

Bibi y, C.J., Burgess, N.D., Hill, D.A. \& Mustoe, S.H. (2000) Bird Census Techniques, 2nd edition. Academic Press, London, UK.

BINFORD, L.C. (1989) A distributional survey of the birds of the Mexican state of Oaxaca. Ornithological Monographs, 43.

Byers, C.R., Steinhorst, R.K. \& Krausman, P.R. (1984) Clarification of a technique for analysis of utilization-availability data. Ornithological Monographs, 48, 1050-1053.

Cantu, J.C., Sanchez, M.A., Grosselet, M. \& Silva, J. (2007) Trafico Ilegal de Pericos en México: Una Evaluación Detallada. Defenders of Wildlife and Teyeliz, Mexico City, Mexico. Http:// pericosmexico.org/publicaciones.html\# [accessed 10 April 2009].

Chávez-Castañeda, N., Gurrola-Hidalgo, M.A. \& GarcíaLópez, J.A. (1996) Catálogo de aves no passeriformes de la colección ornitológica del Instituto de Biología. Universidad Nacional Autónoma de México, Mexico City, Mexico.

Collar, N.J., George, L.P., Krabbe, N., Madroño Nieto, A., Naranjo, L.G., Parker, III, T.A. \& Wege, D.C. (2000) Threatened Birds of the Americas. BirdLife International, Cambridge, UK.

dof (Diario Oficial de la Federación) (2008) Decreto por el que se adiciona un artículo 60 Bis 2 a la Ley General de Vida Silvestre (martes 14 de octubre del 2008). Diario Oficial de la Federación, Mexico City, Mexico. Http://www.dof.gob.mx/ [accessed 1o April 2009].

ENKerLin-Hoeflich, E.C. (1995) Comparative ecology and reproductive biology of three species of Amazon parrots in north-eastern Mexico. PhD thesis, Texas A\&M University, College Station, USA.

Forsha W, J.M. (1989) Parrots of the World, 3rd edition. Lansdown Editions, Willoughby, Australia.

Friedmann, H., Griscom, L. \& Moore, R.T. (1950) Distributional check-list of the birds of Mexico, part I. Pacific Coast Avifauna, 29, 1-202.

GLCF (2010) Global Land Cover Facility. Http://glcf.umiacs.umd.edu/ data/vcf/index.shtml [accessed 2 July 2010].

Howell, S.N.G. (1999) A Bird-Finding Guide to Mexico. Cornell University Press, New York, USA. 
Howell, S.N.G. \& Weвв, S. (1995) A Guide to the Birds of Mexico and Northern Central America. Oxford University Press, Oxford, UK.

IÑgo-Elias, E.E. \& Ramos, M.A. (1991) The psittacine trade in Mexico. In Neotropical Wildlife Use and Conservation (eds J.G. Robinson \& K.H. Redford), pp. 380-392. University of Chicago Press, Chicago, USA.

IUCN (2008) 2008 IUCN Red List of Threatened Species. IUCN, Gland, Switzerland. Http://www.iucnredlist.org [accessed 10 April 2009].

MARSDEN, S.J. (1999) Estimation of parrot and hornbill densities using a point count distance sampling method. Ibis, 141, 377-390.

Marsden, S.J. \& Pilgrim, D. (2003) Factors influencing the abundance of parrots and hornbills in pristine and disturbed forest on New Britain, PNG. Ibis, 145, 45-53.

Martínez-Meyer, E. (2005) Climate change and biodiversity: some considerations in forecasting shifts in species' potential distributions. Biodiversity Informatics, 2, 42-55.

Miller, A.H., Friedman, H., Griscom, L. \& Moore, R.T. (1957) Distributional check-list of the birds of Mexico, part II. Pacific Coast Avifauna, 33, 1-436.

Monterrubio-Rico, T.C., Ortega-Rodríguez, J.M., MarinTogo, M.C., Salinas-Melgoza, A. \& Renton, K. (2009) Nesting habitat of the lilac-crowned parrot in a modified landscape in Mexico. Biotropica, 41, 361-368.

Monterrubio-Rico, T.C., Villaseñor-Gómez, L.E., Marín-Togo, M.C., López-Córdova, E.A., Fabian-Turja, B. \& SoraniDALBón, V. (2007) Distribución histórica y actual del loro cabeza amarilla (Amazona oratrix) en la costa central del pacífico Mexicano, ventajas y limitaciones en el uso de GARP en especies bajo fuerte presión de tráfico. Ornitología Neotropical, 18, 263-276.

Navarro, A.G. (1992) Altitudinal distribution of birds in the Sierra Madre del Sur, Guerrero, Mexico. Condor, 94, 29-39.

Navarro, A.G., Peterson, A.T. \& Gordillo-Martínez, A. (2003) Museums working together: the atlas of the birds of Mexico. Bulletin of the British Ornithological Council, 123, 207-225.

Nue, A.W., Byers, C.R. \& PeEK, J.M. (1974) A technique for analysis of utilization-availability data. Journal of Wildlife Management, 38, 541-545.

Peterson, A.T. (2001) Predicting species geographic distributions based on ecological niche modelling. Condor, 103, 599-605.

Peterson, A.T., Ball, L.G. \& Cohoon, K.P. (2002) Predicting distributions of Mexican birds using ecological niche modelling methods. Ibis, 144, 27-32.

Peterson, A.T., Papes, M. \& Eaton, M. (2007) Transferability and model evaluation in ecological niche modelling: a comparison of GARP and Maxent. Ecography, 30, 550-560.

Phoonjampa, R. \& Brockelman, W.Y. (2008) Survey of pileated gibbon Hylobates pileatus in Thailand: populations threatened by hunting and habitat degradation. Oryx, 42, 600-606.

Renton, K. (2002) Amazona oratrix, Loro cabeza amarilla. In Historia natural de Chamela (eds F.A. Noguera, J.H. Vega-Rivera, A.N. García-Aldrete \& M. Quesada-Avendaño), pp. 343-344. Instituto de Biología, Universidad Nacional Autónoma de México, Mexico City, Mexico.

RIDGELY, R.S. (1981) The current distribution and status of mainland Neotropical parrots. In Conservation of New World Parrots (ed. R.F. Pasquier), pp. 233-384. Smithsonian Institution Press/International Council for Bird Preservation, Washington, DC, USA.

Rios-Muñoz, C.A. (2002) Caracterización geográfica de la familia Psittacidae (Aves) utilizando un modelo predictivo. BSc thesis, Universidad Nacional Autónoma de México, Mexico City, Mexico.

Roet, E.C., Mack, D.S. \& Duplaix, N. (1981) Psittacines imported by the United States (October 1979-June 1980). In Conservation of
New World Parrots (ed. R.F. Pasquier), pp. 21-56. Smithsonian Institution Press/International Council for Bird Preservation, Washington, DC, USA.

Rowley, J.S. (1984) Breeding records of land birds of Oaxaca, Mexico. Proceedings of the Western Foundation of Vertebrate Zoology, 2, 74-224.

Rzedowski, J. (1994) Vegetación de México, 6th edition. Limusa Noriega Editores, Mexico City, Mexico. Http://www.conabio.gob.mx/institucion/centrodoc/doctos/vegetacion_de_mexico.html [accessed 16 July 2010]

SaAd, L., Talhouk, S.N. \& Mahy, G. (2009) Decline of endemic Oncocyclus irises (Iridaceae) of Lebanon: survey and conservation needs. Oryx, 43, 91-96.

Salinas-Melgoza, A. \& Renton, K. (2005) Seasonal variation in activity patterns of juvenile lilac-crowned parrots in tropical dry forest. Wilson Bulletin, 117, 291-295.

SCHAldaCH, JR, W.J. (1963) The avifauna of Colima and adjacent Jalisco, Mexico. Proceedings of the Western Foundation of Vertebrate Zoology, 1, 1-100.

SemarnaP-INE (Secretaría del Medio Ambiente Recursos NatuRales y Pesca-Instituto Nacional de Ecología) (2000) Proyecto de recuperación de especies prioritarias: proyecto nacional para la conservación, manejo y aprovechamiento sustentable de los psitácidos de México. SEMARNAP-INE, Mexico City, Mexico.

SEMARNAP-UNAM (Secretaría del Medio Ambiente Recursos Naturales y Pesca-Instituto de Geografía, Universidad Nacional Autónoma de MÉxICO) (2000) Resultados del inventario forestal nacional 200o. SEMARNAP-UNAM, Mexico City, Mexico.

Stockwell, D.R.B. \& Peters, D.P. (1999) The GARP modelling system: problems and solutions to automated spatial prediction. International Journal of Geographic Information Science, 13, 143158.

Stockwell, D.R.B. \& Peterson, T.A. (2002) Effects of sample size on accuracy of species distribution models. Ecological Modelling, $148,1-13$.

Trejo, I. \& Dirzo, R. (2000) Deforestation of seasonally dry tropical forest: a national and local analysis in Mexico. Biological Conservation, 94, 133-142.

Tsoar, A., Allouche, O., Steinitz, O., Rotem, D. \& Kadmon, R. (2007) A comparative evaluation of presence-only methods for modelling species distributions. Diversity and Distributions, 13, 397-405.

USGS (United States Geological Survey) (2009) HYDROık Elevation Derivative Database. Http://edc.usgs.gov/products/elevation/ gtopo3o/hydro/index.html [accessed 1 July 2010].

Villaseñor-Gómez, J.F. (1988) Aves costeras de Michoacán, México. BSc thesis. Universidad Michoacana de San Nicolás de Hidalgo, Morelia, Mexico.

\section{Biographical sketches}

Tiberio Cesar Monterrubio-Rico is interested in the study and conservation of keystone tropical deciduous forest species, such as parrots. KATHERINE RENTON has conducted research on the ecology and conservation of Neotropical parrots since 1987. JUAN MANUEL ORTEGA-RODRÍGUEz carries out spatial analysis research with a particular interest in ecological niche modelling, currently leading a laboratory focused on remote sensing and geographical information system applications for biodiversity conservation. Alejandro Pérez-Arteaga is interested in conservation planning for birds of conservation and economic interest. RAMón CANCINO-MURILlo's research interests are in the conservation of birds. 